\title{
A Compact Modified Square Printed Planar Antenna for UWB Microwave Imaging Applications
}

\author{
Djamila Ziani, Sidi Mohammed Meriah, Lotfi Merad \\ Faculty of technology, University of Tlemcen \\ Laboratory of Telecommunications Tlemcen (LTT) \\ Tlemcen, Algeria
}

\begin{abstract}
In this paper, both frequency and time domain performances of a new compact planar antenna for the ultrawideband (UWB) applications are fully investigated. The proposed antenna has the size of $12 \times 18 \mathrm{~mm}^{2}$ providing a fractional bandwidth more than $128123 \%(3.057 \mathrm{GHz}$ to 13.98 GHz, S11<-10 dB). The results show that the proposed antenna performances in term of wide bandwidth, small size, gain and radiation pattern, transmission coefficient and system fidelity factor are very satisfactory. Moreover, by fabricating and testing the proposed antenna, the simulation results are fairly verified.
\end{abstract}

Keywords-Modified square planar antenna; high bandwidth; return loss; UWB antenna; low profile; frequency and time domain analysis

\section{INTRODUCTION}

The increased needs of surveillance in different fields led to make the humankind more curious about the unseen and the unknown. In this context, detection through obstacles such as walls, ground or even human tissue has been of a strong interest for the research community. Microwave imaging science has enabled and helped us to resolve these problems. It is actually a good alternative for the other methods of detection [1]. Thanks to their advantages, ultra-wideband is one of the widely used technologies in the microwave imaging systems since the Federal Communication Commission (FCC) allocated the spectrum from $3.1 \mathrm{GHz}$ up to $10.6 \mathrm{GHz}$ in 2002 [2] for this technology communications. It can be defined as any technology using signals that have a bandwidth (BW) greater than $500 \mathrm{MHz}$ or have a fractional bandwidth (FBW) greater than $20 \%$ of the center frequency, as described in (1) and (2) [3].

$$
\begin{gathered}
B W=f_{h}-f_{l} \\
F B W \%=2 * \frac{f_{h}-f_{l}}{f_{h}+f_{l}} * 100
\end{gathered}
$$

Where $f_{h}$ and $f_{l}$ are the higher and the lower frequencies of the operating bandwidth respectively.

As the UWB antenna is the key issue of such systems, plenty of UWB antennas are introduced such as TEM horn, bowtie, spiral antennas and so on [4]-[8]. However, they present some drawbacks in term of bandwidth, size and pulse distortion. For that reason, the necessity of achieving the main requirements of Simplicity, low weight, low cost of fabrication and a wide fractional bandwidth is crucial [9].
Recently micro-strip printed planar antennas attract tremendously many antenna's designers thanks to their interesting characteristics meeting the above criteria, which allow them to be used in emerging UWB applications. This type of antennas consist of a radiating element (patch) which can take several shapes, substrate and ground plane that can be either full or partial. Whereas, they present some limitations in term of the bandwidth, therefore many techniques of bandwidth and impedance matching enhancement are investigated.

In this paper, we propose an UWB small planar antenna for UWB applications that meet the previously mentioned criteria and covers the UWB range. Numerical simulations are conducted to evaluate the antenna performance in both frequency and time domain.

\section{A. Related Work}

The design of an UWB planar antenna for imaging system presents a real challenge. The main problem of this types of antennas is their operational bandwidth and their size. In this fact, a trade-off between the antenna size and the bandwidth is needed.

In the literature, there are fully examples of micro-strip patch antennas such as antenna having a semicircular slotted ground plane [10], new UWB monopole antenna with dual band notched [11], diamond antenna [12], antenna which have a rose leaf structure [13], bow-tie slot antenna for breast cancer detection [14], rectangular ultra-wideband antenna for UWB and different wireless applications [15].

Several techniques are studied and exploited in order to broaden the operating bandwidth, including modifications in ground plane [16], slot-loading techniques [17]. In our work, our purpose lies on designing a small planar antenna which have a wide operational bandwidth relying on the advantage of both partial ground plane and the insertion of slots are exploited.

\section{B. Contributions}

The high bandwidth is an important factor in UWB applications particularly in microwave imaging. In our case, the antenna is intended for array-based imaging system in medical application. A high bandwidth will ensures a good images resolution [18].

Thus, our contributions are:

- High bandwidth is achieved. 
- The proposed antenna provides a good performances in term of gain and the radiation patterns are stable in the desired frequency band.

- The designed antenna has a small size, compact, simple and easy to fabricate which allow it to be integrated easily in array system for medical applications.

This paper is organized as follows: Section II discusses our contributions, describes the antenna design and shows the simulation and experimental results. Sections III and IV are respectively devoted for the frequency and time domain analysis. Finally, Section $\mathrm{V}$ concludes the findings of this paper.

\section{ANTENNA DESIGN AND ANALYSIS}

Fig. 1 presents the geometry of the proposed antenna showing the top and the bottom views of the exponential slot antenna.

The proposed antenna of dimensions $(12 \times 18) \mathrm{mm}^{2}$ is designed on the FR-4 substrate with a dielectric permittivity of $\varepsilon \mathrm{r}=3.38$ and thickness $\mathrm{h}=1.524 \mathrm{~mm}$, with two metallization faces representing the radiating element and a partial ground plane which has a thickness of $\mathrm{t}=0.035 \mathrm{~mm}$. The antenna will be fed by a 50 Ohm micro-strip line.

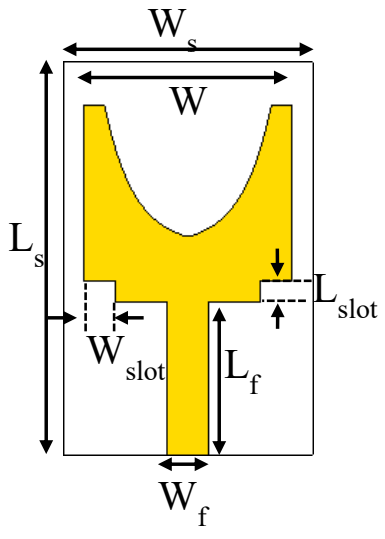

(a)

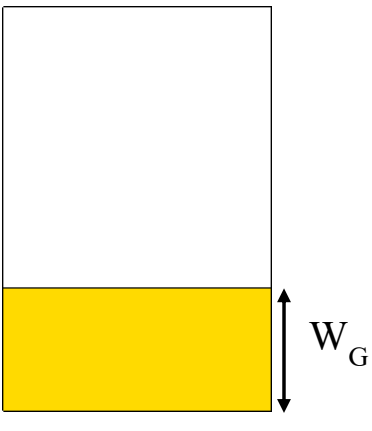

(b)
Fig. 1. Geometry of the proposed antenna. (a) Bottom view, (b) Top view.

- The basic antenna design consists of a simple square patch. First of all, a parametric study was conducted on the length of the ground $\left(\mathrm{W}_{\mathrm{G}}\right.$ parameter) of the ordinary square antenna varying from $3.5 \mathrm{~mm}$ to $5.5 \mathrm{~mm}$, the best results are obtained for $\mathrm{W}_{\mathrm{G}}=4.5 \mathrm{~mm}$ as shown in Fig. 2 .

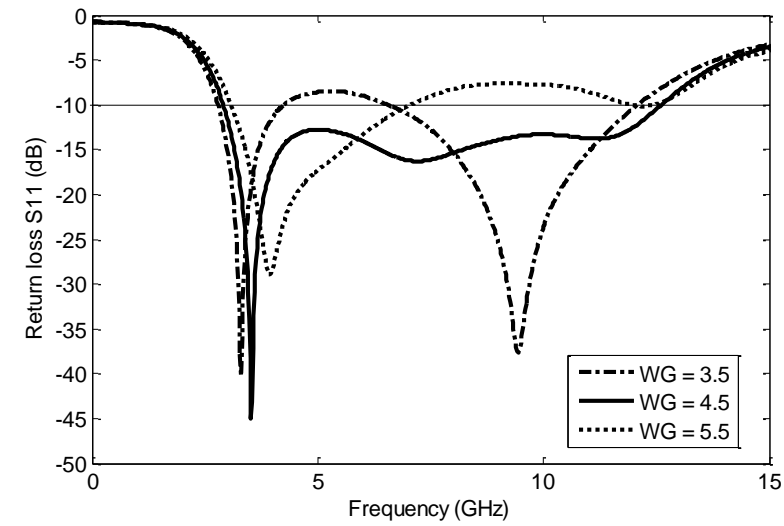

Fig. 2. Return loss parameter for the different values of the ground plane length.

To further enhance the antenna impedance matching and increase the operating bandwidth, we use four rectangular slots which are placed in the edges of the patch and another slot which has an exponential form made with (3). The progress of the design of the antenna, starting from the ordinary square patch to the modified square planar antenna is presented in Fig. 3.

$$
y=c_{1} \cdot e^{R x}+c_{2}
$$

An additional path for surface current is created with the presence of these slots, which leads to producing another resonance, and as a result, increase the bandwidth [19], [20]. The final antenna parameters are illustrated in Table I.

Fig. 4 presents the effect of each variation reaching to the final antenna. It is noticed from the figure that the exponential slot antenna provides a wide fractional bandwidth of more than $128 \%(3.057-13.98 \mathrm{GHz})$.

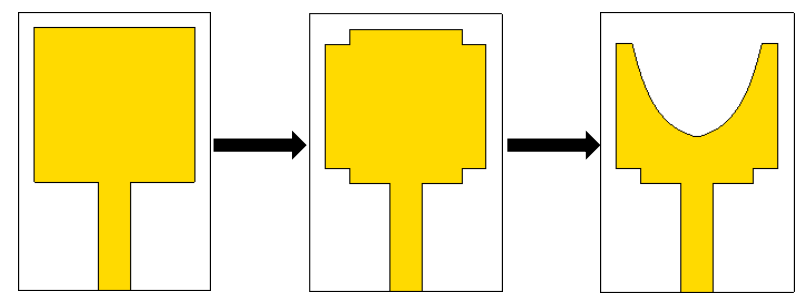

Ant. 1

Ant. 2

Ant. 3

Fig. 3. Progress of the design of the proposed antenna. (Ant. 1) the ordinary square antenna , (Ant. 2) square antenna with rectangular slots and (Ant. 3) final antenna with rectangular and exponential slot. 
TABLE I.

Dimensions of THE DESIGNED ANTENNA

\begin{tabular}{|l|l|}
\hline Variable & Dimension (mm) \\
\hline Ws & 12 \\
\hline Ls & 18 \\
\hline W & 10 \\
\hline Wf & 2 \\
\hline Lf & 7 \\
\hline W $\mathrm{G}$ & 4.5 \\
\hline Lslot & 1 \\
\hline Wslot & 1.5 \\
\hline c1 & 0.698 \\
\hline c2 & 9.302 \\
\hline R & 0.7 \\
\hline
\end{tabular}

The structure is constructed and numerically simulated with the CST MWS software (Computer Simulation TechnologyMicrowaves Studio) [21] and fabricated in our laboratory (Fig. 5). The measured and simulated reflection coefficient of the antenna are plotted in Fig. 6, where we observe evidence of wideband characteristic of the design, defined at threshold limit of $-10 \mathrm{~dB}$ or less. A satisfactory agreement between the measured results and the ones achieved with numerical simulation with small differences, which are probably caused by losses due to the SMA connector used for the measurement taking in account the miniature size of the propose antenna.

The proposed antenna gain is shown in Fig. 7, and as it is apparent the antenna achieves a good gain values in the desired operating frequency band. The maximum gain achieved is over $4 \mathrm{~dB}$.

Fig. 8 shows the radiation patterns of the proposed antenna at different frequencies $(5,8.5$ and $11.5 \mathrm{GHz})$ for both $\mathrm{E}$ and $\mathrm{H}$ planes. The antenna presents acceptable quasi omnidirectional pattern required to receive information signals from all directions.

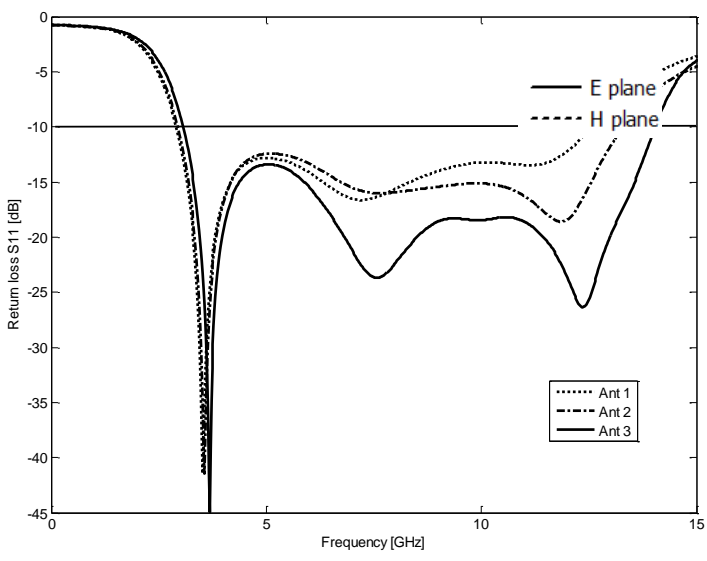

Fig. 4. Return loss parameter for each antenna.
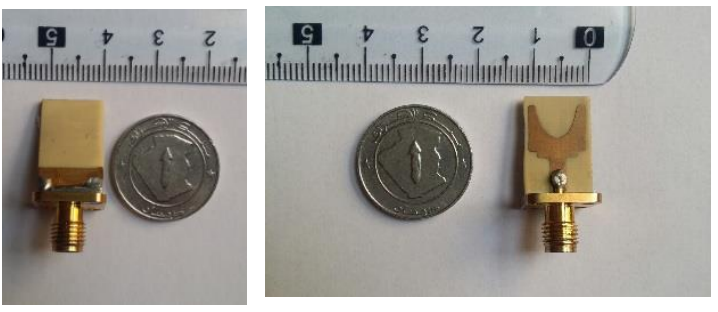

Fig. 5. Fabricated prototype of the antenna (top and bottom view).

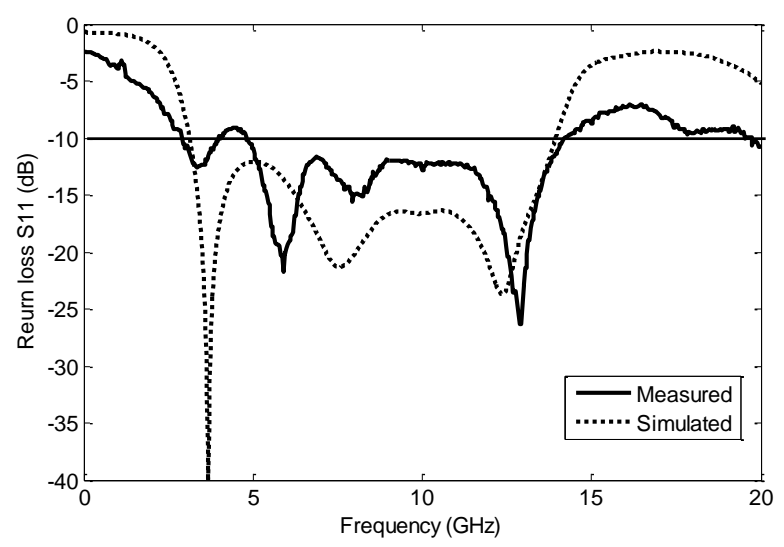

Fig. 6. Measured and simulated return loss of the antenna.

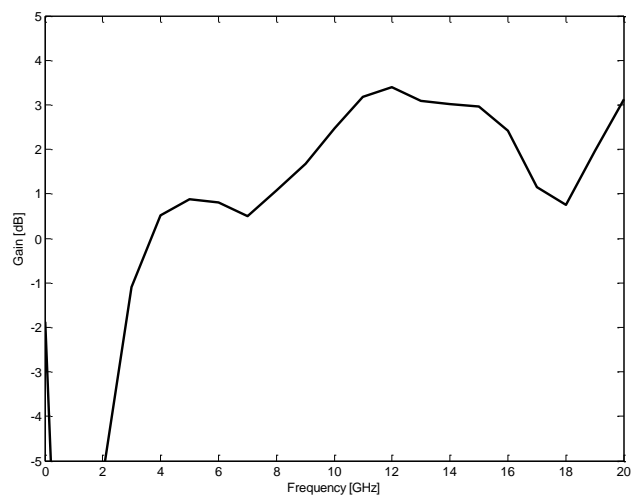

Fig. 7. Antenna gain vs frequency.

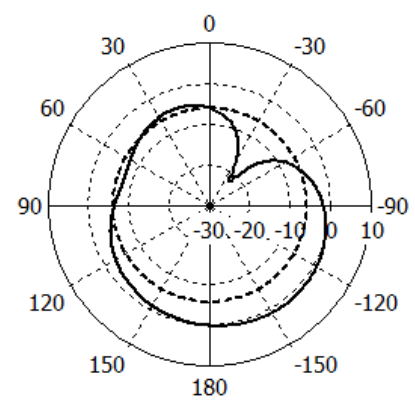

(a) 


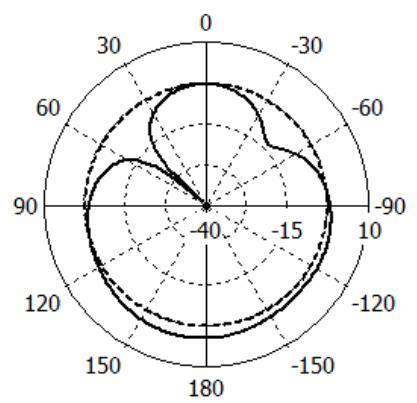

(b)

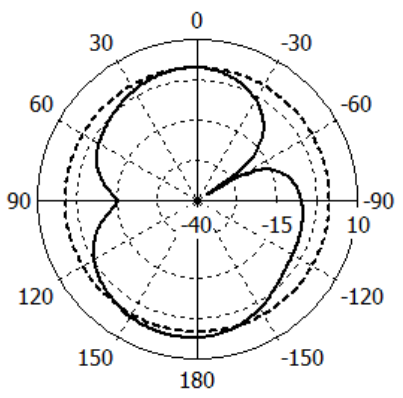

(c)

Fig. 8. 2-D radiation pattern for $\mathrm{E}$ an $\mathrm{H}$ planes at 5, 8.5 and $11.5 \mathrm{GHz}$.

\section{FREQUENCY-DOMAIN ANALYSIS}

The antenna frequency domain characteristics are summarized in the transfer function (transmission parameter $\mathrm{S}_{21}$ ) and the group delay [22]. The transmission coefficient's magnitude and phase should be respectively flat and linear and any distortion will cause signal dispersion. We can evaluate the phase distortion by determining the group delay parameter with the relation

$$
\text { Group delay }=-d \varphi / d f
$$

Where $\varphi$ is $S_{21}$ phase. A constant group delay results to in linear S21 phase.

For that reason, a system of two identical antennas is considered. The antennas are separated by $\mathrm{d}=10 \mathrm{~cm}$ from each other (to have each antenna in the far-field of the other one) and placed in two different orientations, the face to face and side by side orientations (Fig. 9); one of the antennas is the transmitter and the other one act as the receiver.

Fig. 10 presents the simulated transfer function and the group delay for each orientation. It can be seen that the transfer function is flat and the phase is fairly linear over the entire frequency band.
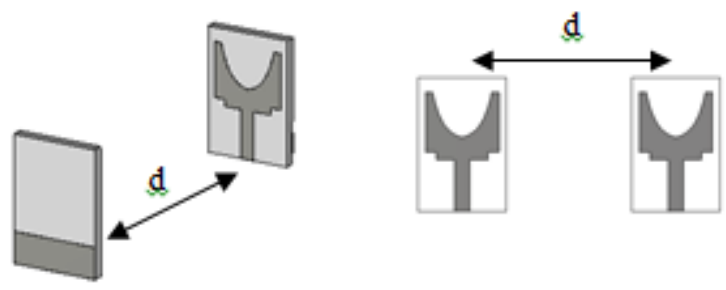

Fig. 9. Antennas orientations (a) face to face (b) side by side.

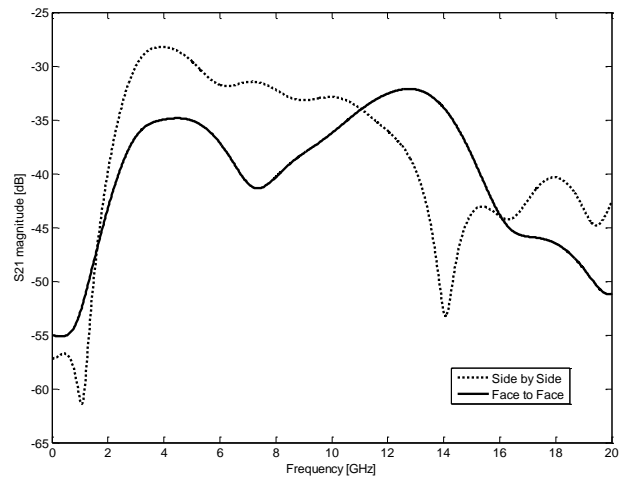

(a)

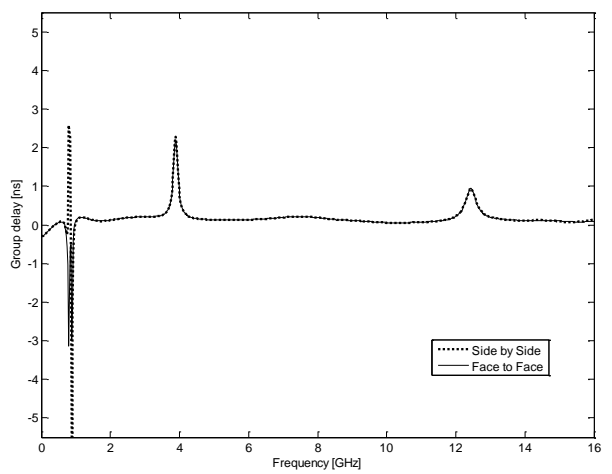

(b)

Fig. 10. (a) Magnitude of S21, (b) Group delay.

\section{TIME-DOMAIN ANALYSIS}

For ultra-wideband antennas, evaluating the time domain behavior and studying the dispersion is very important [11]. For that, a reference signal which meets the FCC mask covering the range from 3.1 up to $10.6 \mathrm{GHz}$, should be applied at the antenna input [9]. The optimal pulse is the one suggested in [23] which has a good corresponding to the FCC mask and it can be obtained by the Gaussian 5th derivative (Fig. 11). Mathematically it can be given by (5):

$y(t)=A\left(-\frac{t^{5}}{\sqrt{2 \pi} \sigma^{11}}+\frac{10 t^{3}}{\sqrt{2 \pi} \sigma^{9}}-\frac{15 t}{\sqrt{2 \pi} \sigma^{7}}\right) \exp \left(-\frac{t^{2}}{2 \sigma^{2}}\right)$

Where $\mathrm{A}$ is a constant chosen to meet the limitations set by the FCC. To cover the right frequency band, the value of $\sigma$ was set at 50.788 ps.

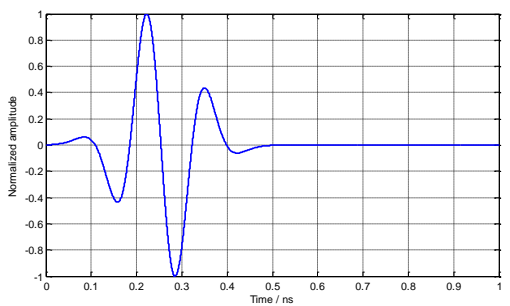

(a) 


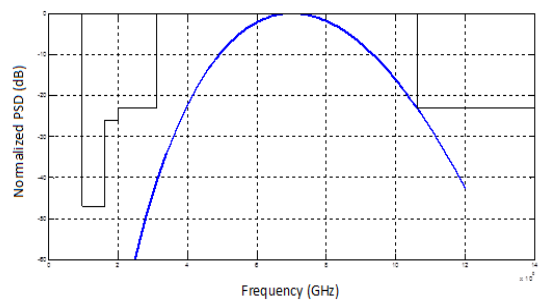

(b)

Fig. 11. The representation of the Gaussian 5th derivative (a) in time domain, (b) spectrum compared with the FCC mask.

The system fidelity factor is one of the most important factors to evaluate the antenna performance [24], [25]. This factor can be defined as the maximum magnitude of the correlation coefficient between the received and the transmitted signals, in fact it can judge the similarity between the two signals. In general, a value less than $0.5(50 \%)$ of the SFF will deliver a high distortion. The system fidelity factor can be evaluated using (6) [26]:

$S F F=\max _{\tau} \frac{\int_{-\infty}^{\infty} s_{t}(t) s_{r}(t-\tau) d t}{\sqrt{\int_{-\infty}^{\infty}\left|s_{t}(t)\right|^{2} d t \int_{-\infty}^{\infty}\left|s_{r}(t)\right|^{2} d t}}$

Where $s_{t}(t)$ and $s_{r}(t)$ are the transmitted and received signals respectively. The normalized transmitted and received signals in the time domain are presented in Fig. 12. System fidelity factor is also calculated according to (6) using Matlab software for the two proposed orientations, and the results are summarized in Table II. We can see that a better system fidelity factor SFF is achieved (more than $92 \%$ ). Therefore, the antenna has no any considerable dispersion.
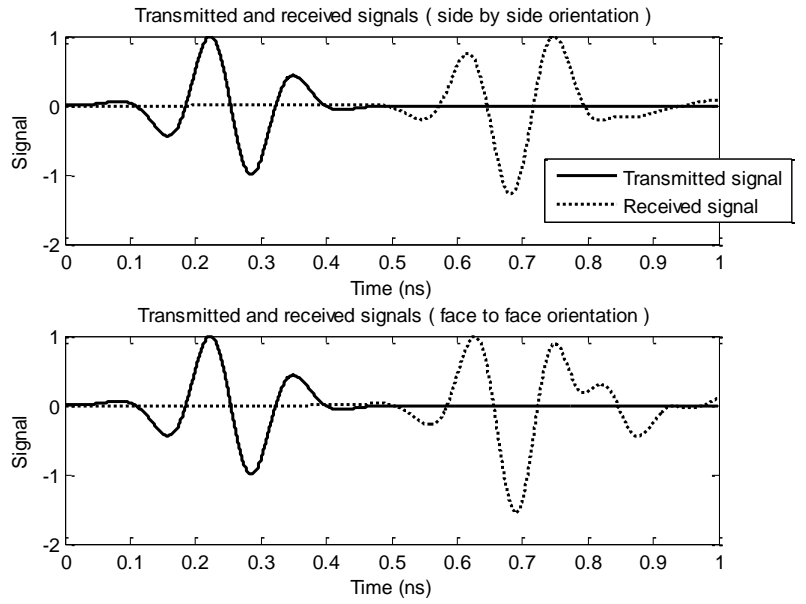

Fig. 12. Normalized transmitted and received signals.

TABLE II. SYSTEM FIDELITY FACTOR OF THE TWO IDENTICAL ANTENNAS BETWEEN THE TRANSMITTED AND RECEIVED SIGNALS

\begin{tabular}{|l|l|}
\hline Variable & Dimension (mm) \\
\hline Side by Side & 0.9525 \\
\hline Face to Face & 0.9246 \\
\hline
\end{tabular}

\section{CONCLUSION AND FUTURE WORK}

In this letter, a compact printed planar UWB antenna for radar and microwave imaging is proposed. The simulation results show that the performance of this antenna meet the desired requirement in terms of return loss parameter, gain, wide bandwidth and radiation pattern. The proposed antenna was fabricated and measured. Good agreement was obtained between simulated and measured data, covering the range from $3.057 \mathrm{GHz}$ to $13.98 \mathrm{GHz}(128 \%)$. The antenna presents a good performance in both time domain and frequency domain, where it exhibits a good system fidelity factor, a flat transfer function and a linear group delay, moreover, it has a low profile $(<2 \mathrm{~cm})$ that can be easily integrated in arrays reducing their dimensions. The results of this antenna confirm that it is suitable for UWB applications. In future work, we aim to use the proposed antenna to design a Radar system for medical imaging applications able to offer a good images resolution benefiting of the UWB characteristis of the our antenna.

\section{ACKNOWLEDGMENT}

The authors would like to gratefully acknowledge Pr. SALAH Belkhoudja from Telecommunications and Digital Signal Processing Laboratory, University of Sidi Belabbes for his technical support in providing the experimental data.

\section{REFERENCES}

[1] S. M. Chouiti, L. Merad, S. M. Meriah, X. Raimundo, A. Taleb-Ahmed, "An Efficient Image Reconstruction Method for Breast Cancer Detection Using an Ultra-Wideband Microwave Imaging System," Electromagnetics, Vol. 36, No. 4, pp. 225-235, 2016.

[2] Federal Communication Commission, "Revision of Part 15 of the Commission's Rules RegardingUltra-Wide-Band Transmission SystemsFirst Report and Order," FCC 02-V48.Tech.Rep, Washington,DC, USA, 2002.

[3] Z. N. C. a. M. Y. W. Chia, "Broadband Planar Antennas, "Design and Applications," John Wiley \& Sons, Ltd, pp. 180-190, 2006.

[4] K. L. Shlager, G. S. Smith, and J. G. Maloney, "Accurate analysis of TEM horn antennas for pulse radiation," IEEE Trans. Electromagn. Compat, Vol. 38, No. 3, 1996.

[5] S. C. Hagness, A. Taflove, and J. E. Bridges, "Wideband ultra low reverberation antenna for biological sensing," Electronics Letters, vol. 33, no. 19, pp. 1594-1595, 1997.

[6] G. E. Atteia and A. A. Shaalan, "Wideband partially-covered bowtie antenna for ground-penetrating-radars," Progress In Electromagnetics Research, PIER 71, 211-226, 2007.

[7] T. W. Hertel and G. S. Smith, "Analysis and design of conical spiral antennas using the FDTD method," Proc. of IEEE Antennas and Propagation Society Int. Symp., Vol. 3, 1540-1543,2000.

[8] J. Ali, N. Abdullah, M. Y. Ismail, E. Mohd and S. Mohd Shah "Ultra Wideband Antenna Design for GPR Applications: A Review," International Journal of Advanced Computer Science and Applications (IJACSA), Vol. 8,No. 7, pp. 392-400,2017.

[9] M. Ershadh, P. Krishna, Bhagyaveni., S. Subramanian, "Design of a Novel Antenna and Its Characterization in Frequency and Time Domains for Ultra Wide Band Applications," Progress In Electromagnetics Research, PIER, Vol. 48., 69-76, 2014.

[10] N. Seladji, F. Z. Marouf, L. Merad, S. M. Meriah, F. T. Bendimerad, M. Bousahla, N. Benahmed, "Antenne Microruban Miniature Ultra Large Bande ULB pour Imagerie Micro-onde", Mediterranean Telecommunication Journal, Vol. 3, No. 1, pp. 21-25, february 2013.

[11] M. Mighani and M. Akbari, "New UWB Monopole Antenna with Dual Band Notched," Progress In Electromagnetics Research C, Vol. 52., 153-162, 2014. 
[12] D. Ziani Kerarti, S. M. Meriah, "New Monopole Antenna for Ultra Wideband Applications", International Journal of Computer Applications, Vol. 47, No. 11, pp. 40-43, 2012.

[13] A.A Lotfi Neyestanak "Ultra WideBand Rose Leaf Microstrip Patch Antenna" Progress In Electromagnetics Research, PIERS 86,pp. 155168,2008

[14] N. Seladji-Hassaine, L. Merad, S. M. Meriah, F. T. Bendimerad, "UWB Bowtie Slot Antenna for Breast Cancer", World Academy of Science, Engineering and Technology, International Journal of Biomedical and Biological Engineering Vol. 6, No. 11, pp. 571-574, 2012.

[15] Z. Ul Abedin and Z. Ullah, "Design of a Microstrip Patch Antenna with High Bandwidth and High Gain for UWB and Different Wireless Applications", International Journal of Advanced Computer Science and Applications (IJACSA), Vol. 8,No. 10, pp. 379-382,2017.

[16] N. PrombutrH, HP. KirawanichH, and P. Akkaraekthalin "Bandwidth Enhancement of UWB Microstrip Antenna with a Modified Ground Plane" International Journal of Microwave Science and Technology, Volume 2009 (2009),

[17] F. Amini and M.N. Azarmanesh, and M. Ojaroudi, Small semicircle-like slot antenna for ultra-wideband applications, Prog Electromagn Res C 13 (2010), 149-158.

[18] A.G. Yarovoy, L.P; Lighart, "UWB Radars: Recent Technological Advances and Applications", IEEE radar conference, pp. 43-48, April 2007.
[19] S. Maci and G. B. Gentili, "Dual frequency patch antennas," IEEE Antennas Propag. Mag., vol. 39, no. 6, pp. 13-20, Dec. 1997.

[20] S. Maci and P. Piazzesi, "Dual-band slot-loaded patch antenna," Proc. Antenna Propag., vol. 142, no. 3, pp. 225-232, Jun. 1995.

[21] CST Microwave Studio, CST Inc .,2014.

[22] A. Mehdipour, K. Mohammadpour-Aghdam, R. Faraji-Dana, "Complete Dispersion Analysis of Vivaldi Antenna for Ultra Wideband Applications," Progress In Electromagnetics Research, 85-96, 2007.

[23] H. sheng, P. Orlik, A.M. Haimovich, L.J. Cimini, Jr, J. Zhang, "On the Spectral and Power Requirements for Ultra-Wideband Transmission," IEEE International Conference on Communications (ICC), December 2003.

[24] G. Quintero, J.F. Zürcher, A.K. Shrivervik, "System Fidelity Factor: A New Method for Comparing UWB Antennas," IEEE transaction on antennas and propagation, Vol. 59, July 2011.

[25] M. Koohestani, A. A. Moreira, A. K. Skrivervik, "Fidelity Concepts Used in UWB Systems" IEEE Antennas and Propagation Society Int. Symp, 2014.

[26] L. Akhoondzadeh-Asl, M. Fardis, A. Abolghasemi, G. Dadashzadeh, "Frequency and Time Domain Characteristics of a Novel Notch Frequency UWB Antenna," Progress In Electromagnetics Research, $337-348,2008$ 